\title{
The Strategic Plan in action
}

\author{
By the ACRL Planning Committee
}

Carolyn Dusenbury, Immediate Past Chair

\section{ACRL looks to the future.}

\section{$\mathbf{T}$}

his is the second of a series of annual Strategic Planning reports to the members of ACRL. During the past year, the planning process has been moving ahead much faster than during the initial year, with a large part of the credit due to the committees and sections of ACRL. Each unit was asked to complete the Strategic Planning Inventory which established where the projects and activities of the unit fit into the Plan and indicated areas where the Plan needed to be expanded and updated. This information, gathered annually, is essential to an effective and current planning process. Planning Committee very much appreciates the time, thought, and cooperation exhibited by committees and sections in making the Plan successful.

Many ACRL units commented last year that the information requested in the Strategic Planning Inventory was duplicated in the documentation forwarded by units when they are reviewed by the Planning Committee every three years. This information was very helpful to the Planning Committee in its attempts to keep redundant reporting to a minimum. The Planning Committee reviewed and clarified the intent of each of the reports and agreed with the units that most of the information in the Inventory did not need to be repeated when a unit was reviewed. As a result, the review forms for committees and sections has been completely overhauled so that units are not required to submit the same information twice.

The ACRL Strategic Plan consists of four broad goals with more specific subgoals for meeting each of the goals. Each subgoal is moved forward by a set of annual objectives which ensure progress on the goals. The goals, subgoals, and objectives are reviewed annually and the objectives are updated to keep the Plan moving ahead. Each year the current year is evaluated and a new year is added to the Plan. In addition to the annual review and updating process for each goal, the Planning Committee will do an indepth review of one of the four goals in an attempt to prevent the plan from being each year's "bits and pieces" rather than an integrated endeavor that is integrated within each of the goals.

The four major strategic planning goals are to: 1 ) contribute to the total professional development of academic and research librarians; 2 ) enhance the capability of academic and research libraries to serve the needs of users; 3 ) promote and speak for the interests of academic and research librarianship; and 4) promote study, research, and publication relevant to academic and research librarianship. Many of the subgoals and objectives address the five areas-publications, continuing education, standards, liaisons and chapters-which were ranked as the highest needs and priorities of the membership at the 1985 ACRL President's Program. To keep up with the needs and interests of the membership, the ACRL Membership Committee conducts a needs assessment every five years. The needs assessment, in identifying the priorities of the membership for the Planning 
Committee and ACRL, ensures that ACRL continues to fulfill its mission to its membership.

During the past year, the Planning Committee has undertaken its first environmental scan. An environmental scan is the product of the collection of relevant data on social, economic, technological, and other developments over an extended period of time. This basic component of strategic planning is used to identify trends and forecast their possible impact on the organization. Information is obtained from general sources such as newspapers and weekly news magazines, specialized publications relevant to ACRL, reviews of research proposals and funded research, and publications of forecasting organizations. The scan is used to develop long-term strategies and directions in light of the external factors that will have an impact on ACRL. The first strategic plan will be submitted to $C \& R L$ News for publication.

The planning process also identifies seven "Strategic Management Directions," which address important issues such as membership services, management of financial resources, support for the officers of ACRL, effectiveness of ACRL staff. Two of these management directions are: "Position ACRL as the most significant American association of academic and research libraries, librarians, and librarianship - the association which represents them, speaks for them, asserts their interests, and assists them in reaching their goals" and "work collaboratively with other ALA units for the good of librarianship as a whole."

\section{Evaluating information sources}

In conjunction with the 18th National LOEX Library Instruction Conference to be held May 11-12, 1990, in Ypsilanti, Michigan, abstracts for a series of 30 -minute practical instructive sessions are being sought. The sessions should deal with specific methods or strategies for teaching students how to evaluate sources of information in print and/or electronic format. Each abstract must include an idea for an exercise or be accompanied by a sample exercise for participants to complete.

Some suggested topics are: evaluating indexes; how to study reference sources; preparing research topic worksheets; assessing reviewer bias; evaluating books; author's credentials; evaluating journal vs. magazine articles. Interested presenters should submit a one-page abstract with a proposed title, audiovisual requirements, name, address, and phone number by December 15, 1989, to: Director, LOEX Clearinghouse, Eastern Michigan University Library, Ypsilanti, MI 48197; (313) 487-0168.
Each year the ACRL President-elect and the Board of Directors reviews the goals and the Strategic Management Directions to establish the planning priorities for the year. The incoming President-elect meets with the Planning Committee at the Annual Conference to discuss the Presidentelect's priorities and the areas identified by the Board as priorities. From these discussions the Planning Committee prepares a recommendation for the consideration of the Board.

\section{Priorities for 1990}

ACRL President Bill Moffett and the Board agreed at the Annual Conference in New Orleans that the priority area for the fiscal years 1990 and 1991 should be the following parts of Goal III of the Strategic Plan:

Subgoal A. To enhance awareness of the role of academic and research libraries among non-library professionals and organizations.... and to develop effective working relationships with them.

Subgoal C. To support and participate in the recruitment and retention of outstanding persons to the field of academic and research librarianship. These priorities will be reflected in the Strategic Plan by identifying existing activities in these areas and developing new objectives, if necessary, to realize these goals.

\section{Priorities for 1991}

ACRL President-elect Barbara Ford has proposed information literacy as her priority for her presidential term. In discussions with the Planning Committee, Goal II, Subgoals C and D, and Goal IV of the Strategic Plan were identified. Goal II is "To enhance the capability of academic and research libraries to serve the needs of users." Subgoal $C$ is: "Toidentify, explore, and act on problems and issues facing academic and research libraries"; and Subgoal D is: "To encourage and evaluate innovation in library operations and services." Goal IV is: "To promote study, research, and publication relevant to academic and research librarianship." As with the 1990 priorities, the Planning Committee will be reviewing the information gathered from ACRL units in the Inventory, incorporating the special projects initiated by the President, and recommending to the ACRL Board otherways that these priorities can be pursued in 1991 .

If you would like further information on the planning process or if you would like to make any comments or suggestions, you are encouraged to contact ACRL or the Chair of the Planning Committee: Michael Kathman, Director of Libraries, Media and Academic Computing, St. John's University/College of St. Benedict, Collegeville, MN 56321 . 